limiting infarct size and augmenting blood flow to additional jeopardised zones. ${ }^{4}$ Moreover, since the use of thrombolytic agents and aspirin in patients with myocardial infarction improves short and long term survival we would expect to have to give any additional treatment for a longer period to a larger number of patients to show a further reduction in mortality.

On the other hand, an adverse influence of giving angiotensin converting enzyme inhibitors early after myocardial infarction might result from systemic or direct myocardial effects of these agents. Systemic hypotension may reduce coronary perfusion; in the CONSENSUS II trial there was an increased incidence of first dose hypotension in the enalapril group (10.5\% v $2.5 \%$ in placebo group) and mortality was increased in patients who showed this effect. Myocardial angiotensin II increases the rate of myocardial protein synthesis, promotes growth of myocytes, and promotes collagen expression by fibroblasts, ${ }^{8.10}$ and large increases in angiotensin converting enzyme activity are found in the scar tissue after myocardial necrosis. "In the short term these effects may serve to maintain cardiac structural integrity and normalise cardiac performance, in part by augmenting chamber compliance. Thus angiotensin converting enzyme inhibitors may actually worsen clinical outcome by inhibiting an early protective effect of angiotensin II on cardiac structure.

Do the data from the CONSENSUS II study provide conclusive proof that giving an angiotensin converting enzyme inhibitor early produces no survival benefit? The findings certainly highlight the risk of hypotension; elderly people and patients with inferior myocardial infarction have a greater propensity for this complication. On the other hand, an echocardiographic substudy showed that the increase in ventricular volume was significantly reduced in the six months after myocardial infarction, presumably because of attenuation of remodelling-as supported by the data from the SOLVD prevention and the SAVE studies. The factors that could potentially have been influenced by early angiotensin converting enzyme inhibitor treatment are infarct size and expansion, and we have no specific data on these. Indeed, the effect of early treatment on infarct size and expansion may be seen only in subgroups of patients, and future studies should be directed at identifying such groups.

Though many issues remain to be resolved, data from the SOLVD prevention and SAVE trials provide compelling evidence that patients recovering from myocardial infarction with asymptomatic left ventricular systolic dysfunction (ejection fraction equal to or less than $40 \%$ ) benefit from long term administration of an angiotensin converting enzyme inhibitor. While routine, early administration of angiotensin converting enzyme inhibitors cannot presently be recommended in patients with acute myocardial infarction, this strategy needs further evaluation in high risk subgroups, especially patients with large, first anteroapical infarction.

MANI A VANNAN Research Fellow

Cardiac Department,

DERYCK J E TAYLOR

Kent and Canterbury Hospital,

Canterbury CT1 3NG

MICHAEL $M$ WEBB-PEPLOE Consultant Cardiologist

Department of Cardiology,

St Thomas's Hospital,

London SE1

Division of Cardiology,

Tufts University,

New England Medical Center,

Boston, MA 02111,

USA

1 Pfeffer MA, Pfeffer JM, Steinberg CR, Finn P. Survival after an experimental myocardial infarction: beneficial effects of long-term therapy with captopril. Circulation 1985;72:406.

2 Pfeffer MA, Lamas GA, Vaughan DE, Parisi AF, Braunwald E. Effect of captopril on progressive ventricular dilatation after anterior myocardial infarction. $N$ Engl $\mathcal{Y}$ Med 1988;319:80-6.

3 Sharpe N, Smith H, Murphy J, Greaves S, Hart H, Gamble G. Early prevention of left ventricular dysfunction after myocardial infarction with angiotensin-converting-enzyme inhibition. Lancet 1991;337:872-6.

4 Vannan MA, Taylor DJE. Ventricular remodelling after myocardial infarction. Br Heart $\mathcal{f}$ 1992;68:257-9.

5 Pfeffer MA, Braunwald E, Moyé LA, Basta L, Brown EJ, Cuddy TE, et al. Effect of captopril on mortality and morbidity in patients with left ventricular dysfunction after myocardial
infarction-results of the survival and ventricular enlargement trial. $N$ Engl $\mathcal{F}$ Med 1992;327: 669-77.

6 The SOLVD Investigators. Effects of enalapril on mortality and the development of heart failure in asymptomatic patients with reduced left ventricular ejection fractions. $N$ Engl $\mathcal{J}$ Med 1992;327:685-91

7 Swedberg K, Held P, Kjekshus J, Rasmussen K, Ryden L, Wedel $\mathbf{H}$. Effects of the early administration of enalapril on mortality in patients with acute myocardial infarction: results of the cooperative new Scandinavian enalapril survival study II (CONSENSUS II). $N$ Engl 8 Med 1992;327:678-84

8 Khairallah PA, Kanabus J. Angiotensin and myocardial protein synthesis. In: Tarazi RC, Dunbar JB, eds. Perspectives in cardiovascular research. Vol 8. New York: Raven Press, 1983:337-47.

9 Aceto JF, Baker KM (Sar). Angiotensin II receptor-mediated stimulation of protein synthesis in chick heart cells. Am F Physiol 1990;258:H806-13.

10 Weber KT, Brilla CG. Pathological hypertrophy and cardiac interstitium: fibrosis and reninangiotensin-aldosterone system. Circulation 1991;83:1849-65.

11 Johnston CI, Mooser V, Sun Y, Fabris B. Changes in cardiac angiotensin converting enzyme after myocardial infarction and hypertrophy in rats. Clin Exp Pharmacol Physiol 1991;18:107-10.

\title{
The thrifty genotype in non-insulin dependent diabetes
}

\section{The hypothesis survives}

In 1962 Neel proposed that the persistence of diabetes mellitus must mean that the diabetic genotype holds some survival advantage. ${ }^{1}$ Two decades later, after the clearer recognition of the distinction between insulin dependent and non-insulin dependent diabetes mellitus, Neel modified his hypothesis so that it related specifically to non-insulin dependent diabetes. ${ }^{2}$ Despite some scepticism, the "thrifty genotype" remains a convenient explanation for the extremely high incidence of non-insulin dependent diabetes that develops in many populations which have experienced rapid socioeconomic modernisation during this century. ${ }^{3-6}$

The thrifty genotype is thought to have offered a survival advantage to individuals in hunter-gatherer and early agri- cultural societies, who were subject to periods of nutritional hardship, by favouring fat deposition during periods when food was abundant. In modern times, when physical activity has decreased and calories are in constant supply (usually in an energy dense form high in fat and simple carbohydrates), the genotype has become disadvantageous and favours the development of obesity and non-insulin dependent diabetes. ${ }^{24}$ Central to the need for the thrifty genotype hypothesis is the assumption that, when expressed, non-insulin dependent diabetes was associated with diminished fertility (at least before the advent of modern medicine). Certainly, a reproductive handicap has recently been shown in young Nauruan women with early onset non-insulin dependent diabetes. ${ }^{7}$ 
Whether or not humans with a thrifty genotype did in the past (or continue to) better survive periods of famine has not been directly proved. This assumption rests largely on the observation of high susceptibility to non-insulin dependent diabetes in populations known historically to have experienced such episodes. North American Indians, ${ }^{8}$ Polynesian and Micronesian Pacific islanders, ${ }^{347}$ Australian Aborigines, ${ }^{9}$ and Asian Indians ${ }^{1011}$ are usually considered in these terms, but it is not known whether all human populations previously subject to severe "feast and famine" conditions have a thrifty genotype.

Recently some migrant African and Chinese populations have also been found to be susceptible to non-insulin dependent diabetes, ${ }^{11}$ and people of European origin might be the only true "low susceptibility" group. As Weatherall suggested in his 1992 Harveian oration, ${ }^{6}$ this implies either that the positive selective forces favouring the thrifty genotype were not as strong in Europeans or that the negative selective forces of a sedentary, well nourished lifestyle have operated for sufficiently long to diminish the frequency of the genotype. Whatever the case, non-insulin dependent diabetes in Europeans tends to occur in middle or older age, after completion of the reproductive phase in women, and contrasts with the early age of onset and severity of the disease observed in populations such as Nauruans. ${ }^{7}$

Experimental support for the thrifty genotype comes from work in rodents showing that strains susceptible to obesity and diabetes have lower metabolic rates, defective thermoregulatory mechanisms, and an enhanced ability to store food as fat and to survive prolonged fasting. ${ }^{12}$ Prospective studies in Pima Indians indicate that "thrifty" lower metabolic rates in humans may favour weight gain. ${ }^{13}$ The metabolic expression of the thrifty genotype favouring non-insulin dependent diabetes would appear to be via selective tissue insulin resistance and relatively high basal and stimulated insulin concentrations. Under modern conditions these promote obesity and a vicious cycle of increasing insulin resistance and compensatory hyperinsulinaemia, leading ultimately to pancreatic $\beta$ cell decompensation and frank diabetes. ${ }^{4}$

Adapting data from known insulin resistant states such as obesity and non-insulin dependent diabetes, O'Dea has recently theorised on the nature of metabolic adaptations which might have favoured survival in Australian Aborigines in the context of their traditional hunter-gatherer diet, where "feasts" on wild animals such as kangaroos were characteristically high in protein and relatively low in fat and carbohydrate. ${ }^{9}$ In this case, selective insulin resistance in liver would promote conversion of dietary protein to glucose and fat via active hepatic gluconeogenesis, which is not sensitive to insulin suppression, and lipogenesis, which is insulin sensitive. Meanwhile, fat accumulation would be encouraged by insulin sensitive adipose tissue and the relative resistance to glucose uptake in skeletal muscle. ${ }^{9}$ This concept of selective insulin resistance is not new and has been well demonstrated in animal models. ${ }^{12}$

In a recent publication Wendorf and Goldfine have related apparent variation in susceptibility to non-insulin dependent diabetes among North American Indian tribes to the timing of migrations into the continent. ${ }^{8}$ They have hypothesised that a "thrifty genotype" may have been selected around 10000-11000 years ago in a subgroup of ancestral Indians with a particular reliance on vanishing big game species such as mammoths. While difficult to prove, the development of such hypotheses at least indicates that researchers are attempting to justify reliance on the thrifty genotype to explain variation in non-insulin dependent diabetes frequency.

In Pima Indians a considerable body of work favours a selective insulin resistance in muscle as the metabolic expression of the thrifty genotype. This includes the demonstration that insulin action appears to aggregate in families ${ }^{14}$ and that its distribution is compatible with a single gene codominant mode of inheritance. ${ }^{15}$ None the less, except for specific mutations to key enzymes in rare syndromes of familial diabetes and the recently identified link between some kindreds of maturity onset diabetes of the young and mutations to the glucokinase gene in liver and $\beta$ cells, ${ }^{16}$ the gene(s) causing the bulk of cases of non-insulin dependent diabetes remain obscure. While a single defect may be responsible in small unique populations such as Pima Indians and Nauruans, ${ }^{34}$ in larger high prevalence populations a polygenic causation is most likely.

It would be too much to expect convergent evolution to have produced a single thrifty genotype in all populations by chance, and the most likely situation is that several genes have been selected in different combinations, in different populations, to produce a phenotypically similar syndrome. ${ }^{268}$

The search for the genes responsible for non-insulin dependent diabetes continues and may one day offer the option of high risk or even general population screening, and perhaps specific gene manipulation therapies. However, even now the epidemiological evidence for the disadvantages of a sedentary lifestyle and Western diet in causing current epidemics of obesity and non-insulin dependent diabetes in the developing world provides a compelling basis for promoting primary prevention of these diseases. ${ }^{4}$ Certainly, preventive strategies and modern medicine will tend to counteract negative selective forces and will maintain the frequency of the thrifty genotype in human populations, but, as Neel soberly pointed out, "efforts to preserve the diabetes genotype through this transient period of plenty are in the interests of mankind," for some time in the future we may again be glad to have it.

GARY DOWSE

Epidemiologist

PAUL ZIMMET

Director

International Diabetes Institute,

Caulfield, Victoria 3162

Australia

1 Neel JV. Diabetes mellitus: a thrifty genotype rendered detrimental by 'progress'? Am $\mathcal{f}$ Hum Genet 1962;14:353-62.

2 Neel JV. The thrifty genotype revisited. In: Kobberling J, Tattersall R, eds. The genetics of diabetes mellitus. Proceedings of the Serono symposium. London: Academic Press, 1982:283-93.

3 Zimmet P, Dowse G, Serieantson S, Finch C, King H. The epidemiology and natural history of NIDDM - lessons from the South Pacific. Diabetes Metab Rev 1990;6:91-124.

4 Zimmet P. Challenges in diabetes epidemiology-from West to the rest. Diabetes Care 1992;15: 232-52.

5 Diamond JM. Diabetes running wild. Nature 1992;357:362-3.

6 Weatherall D. The Harveian Oration. The role of nature and nurture. London: Royal College of Physicians, 1992.

7 Dowse GK, Zimmet PZ, Finch CF, Collins V. Decline in incidence of epidemic glucose tolerance in Nauruans: implications for the "thrifty genotype." Am f Epidemiol 1991;133:1093-104.

Wendorf M, Goldfine ID. Archaeology of NIDDM. Excavation of the "thrifty" genotype. Diabetes 1991;40:161-5.

9 O'Dea K. Westernisation, insulin resistance and diabetes in Australian Aborigines. Med $\mathcal{f}$ Aust 1991;155:258-64.

10 King H, Rewers M, WHO Ad Hoc Diabetes Reporting Group. Global estimates for prevalence of diabetes mellitus and impaired glucose tolerance in adults. Diabetes Care 1993;16:157-77.

1 Dowse GK, Gareeboo H, Zimmet PZ, Alberti KGGM, Tuomilehto J, Fareed D, et al. High prevalence of NIDDM and impaired glucose intolerance in Indian, Creole and Chinese Mauritians. Diabetes 1990;39:390-6.

12 Shafrir E. Nonrecognition of insulin as gluconeogenesis suppressant - a manifestation of selective hepatic insulin resistance in several animal species with type II diabetes: sand rats, spiny mice and $d b / d b$ mice. In: Shafrir E, Reynolds AE, eds. Frontiers in diabetes research. Lessons from animal diabetes II. London: John Libbey, 1988:304-15.

13 Ravussin E. Energy metabolism in obesity. Studies in the Pima Indians. Diabetes Care 1993;16(suppl 1):232-8.

14 Lillioja S, Mott DM, Zawadski JK, Young AA, Abbott WGH, Knowler WC, et al. In vivo insulin action is familial characteristic in nondiabetic Pima Indians. Diabetes 1988;36:1329-35.

15 Bogardus C, Lillioja S, Nyomba BL, Zurlo F, Swinburn B, Puente AE-D, et al. Distribution of in vivo insulin action in Pima Indians as mixture of three normal distributions. Diabetes 1989;38:1723-32.

16 Vionnet N, Stoffel M, Takeda J, Yasuda K, Bill GI, Zouali H, et al. Nonsense mutation in the glucokinase gene causes early-onset non insulin-dependent diabetes mellitus. Nature 1992;356: $721-2$. 